\title{
The Cognitive Architecture of Imaginative Resistance
}

\author{
Kengo Miyazono \& Shen-yi Liao \\ The Routledge Handbook of Philosophy of Imagination (forthcoming) ${ }^{\dagger}$
}

Very roughly, imagination is the attitude with which we think about possibilities, reason counterfactually, construct pretense scenarios, and engage with stories and other representational artworks. As a part of our mental repertoire, it interacts with beliefs, desires, emotions, and other attitudes and processes to allow us to engage in a rich array of activities. (We will say more about imagination in section 1.)

Very roughly, imaginative resistance is the phenomenon in which we, who are otherwise competent imaginers, experience a constraint in taking part in an imaginative activity. Philosophers have focused primarily on when people experience imaginative resistance in response to stories. For example, if a story simply states that "in killing her baby, Giselda did the right thing; after all, it was a girl" without any additional context, then many readers are likely to experience a constraint in imaginatively engaging with this story. (We will say more about imaginative resistance in section 2.)

So, where is imagination in imaginative resistance?

In this handbook chapter, we seek to answer this question by connecting two ongoing lines of inquiry in different subfields of philosophy. In philosophy of mind, philosophers have been trying to understand imagination's place in cognitive architecture. In aesthetics, philosophers have been trying to understand the phenomenon of imaginative resistance, especially in connection with fictional narratives. By connecting these two lines of inquiry, we hope to achieve mutual illumination of an attitude and a phenomenon that have vexed philosophers.

Our strategy is to reorient the imaginative resistance literature from the perspective of cognitive architecture. ${ }^{1}$ Existing taxonomies of positions in the imaginative resistance literature (for example, Liao and Gendler forthcoming) have focused on disagreements over the source and scope of the phenomenon-mainly, with respect to the question of when imaginative resistance arises. In contrast, our proposed taxonomy focuses on the psychological components necessary for explaining imaginative resistance.

\footnotetext{
* The authors are equal contributors; they are listed reverse-alphabetically. We thank Adriana Clavel Vazquez, Anna Ichino, Amy Kind, Shannon Spaulding, and Nils-Hennes Stear for their careful, incisive comments on earlier versions of this chapter.

† Penultimate Version. For citation and reference, please see the definitive and final version in Amy Kind (ed.), The Routledge Handbook of Philosophy of Imagination.

${ }^{1}$ We are inspired by the approach that Jonathan Weinberg and Aaron Meskin (2006) take to puzzles that involve imagination: "it should hardly be surprising that many puzzles of the imagination might begin to dissolve with the appropriate application of cognitive science. The imagination, after all, is a faculty that creatures like us contingently possess and deploy in distinctive ways" (177). Currie and Ichino (2013) also pursue this strategy in their brief discussion of imaginative resistance.
} 
We start by characterizing the attitude and the phenomenon under discussion. In section 1, we explain the cognitive architectural framework that guides this handbook chapter, and clarify the sense of imagination that is relevant to our discussion. In section 2, we give an overview of imaginative resistance. We then offer a new taxonomy of accounts of imaginative resistance based on their cognitive architectural commitments. In section 3, we examine cognitive imagination (or belief-like imagination) accounts. In section 4, we examine conative imagination (or desire-like imagination) accounts. In section 5, we examine accounts of imaginative resistance that do not fundamentally involve any imaginative attitudes. We conclude, in section 6 , by gesturing toward directions for further research.

\section{Imagination}

\subsection{Imagination as a Propositional Attitude}

Imagination's nature is surprisingly mysterious. Surprising because it is so widely discussed and invoked in theories - in philosophy of mind, in epistemology, in aesthetics, and in ethics (Gendler 2011). Mysterious because even the experts have a hard time finding a unifying concept from the various uses. For example, in Mimesis as Make-Believe, the text that has arguably become the reference point for contemporary philosophical discussions of imagination, Kendall Walton (1990: 19) writes,

What is it to imagine? We have examined a number of dimensions along which imaginings can vary; shouldn't we now spell out what they have in common?-Yes, if we can. But I can't.

In this dispiriting spirit, numerous other philosophers-including Gendler (2011), Kind (2013), and Van Leeuwen (2013) - have commented on the heterogeneity of imagination. Hence, instead of tackling the incredibly difficult, if not impossible, project of delineating a central concept of imagination, we will simply stipulate the sense of imagination that will be relevant to our discussion.

We will talk about imagination in its attitudinal sense-as a component of one's cognitive architecture. As an attitude, imagination is located at the same explanatory level as other commonly recognized folk psychological attitudes such as belief and desire. Specifically, we will talk about imagination as a propositional attitude-it, like belief and desire, takes propositions as its content. Of course, there are many other senses of imagination (see Gendler 2011 and Van Leeuwen 2013 for a sample), but we will set them aside in this handbook chapter. Even with this narrow focus, there remain significant and substantial debates about the nature of imagination; these are debates about imagination's place in cognitive architecture. 


\subsection{Cognitive Architecture}

A cognitive architecture is a theory about the mind at the functional-as opposed to, say, neurological or biological-level that aims to explain relevant psychological phenomena. By (literally) drawing out the functional connections between various components of the mind-a practice that is sometimes (derisively) called 'boxology' - a cognitive architecture highlights psychological laws at the functional level. ${ }^{2}$

On a familiar analogy, attitudes - such as belief, desire, and imaginationare containers of content. Each attitude is associated with a set of characteristic functions, or inputs and outputs. Mental states-such as specific beliefs, desires, and imaginings-are combinations of a container and a content, which is typically a proposition. Note that the container metaphor is misleading in one respect: not every mental state can be neatly slotted into a container. Instead, a mental state only needs to exhibit enough of the characteristic functions of an attitude to count, and ambiguous cases are common.

\subsection{Cognitive Architectural Debates about the Imagination}

In contemporary discussion, there are two prominent debates about imagination as a component of cognitive architecture (Liao and Doggett 2014). The first debate concerns the existence of an imaginative attitude that is "belief-like", which we will call cognitive imagination. The second debate concerns the existence of an imaginative attitude that is "desire-like", which we will call conative imagination. For an example of each, consider what happens when one pretends to be Romeo in the final act of Romeo and Juliet: one cognitively imagines that Juliet is dead, and consequently one also conatively imagines that Romeo is dead too.

There are a number of features that can make these respective imaginative attitudes belief-like or desire like, such as functional roles, inferential patterns, and directions-of-fit. For example, some defenders of both cognitive and conative imagination say that pairs of cognitive and conative imaginings can generate actions and emotions in the same way that pairs of beliefs and desires can; and that's the sense in which these imaginative attitudes are, respectively, belief-like and desire-like (Doggett and Egan 2007, 2012).

The dominant position in this literature accepts cognitive imagination but rejects conative imagination (for example, Funkhouser and Spaulding 2009; Nichols and Stich 2003; Kind 2011; Weinberg and Meskin 2006a, 2006b). A notable minority

\footnotetext{
${ }^{2}$ The name 'boxology' comes from diagrammatic representations of cognitive architectures, in which attitudes are typically represented by boxes and their functions are typically represented by arrows from one box to another. The deployment of cognitive architecture in psychological explanations involves some assumptions that are controversial in the broader context of philosophy of mind. Most glaringly, this discussion assumes that it makes sense to theorize about the mind - at least with respect to propositional attitudes-at the functional level. That is, this discussion assumes that attitudes can be, at least partially, characterized by their functional roles-their dispositions to causally interact with other components of the mind in particular ways. However, since all discussions of the psychology of imaginative resistance occur at the functional-as opposed to, say, neurological or biological-level, these assumptions can be safely adopted in the present context.
} 
accepts both cognitive and conative imagination (for example, Doggett and Egan 2007, 2012; Currie and Ravenscroft 2002). Another notable minority rejects both cognitive and conative imagination as distinctive, sui generis attitudes (for example, Langland-Hassan 2012, 2014; Leslie 1987, 1994; and plausibly also Gendler 2008a, 2008b). As far as we know, despite the logical possibility, no one accepts conative imagination but rejects cognitive imagination. Finally, of course, there exist a variety of positions that do not fall neatly into this taxonomy (for example, Schellenberg 2013; Van Leeuwen 2011).

The broader debate between these positions on imaginative attitudes primarily turns on the respective cognitive architectures' ability to explain relevant psychological phenomena. In the context of this broader debate, imaginative resistance is one psychological phenomenon that can be used to test different cognitive architectures' explanatory power and empirical adequacy. For example, all else being equal, if it turns out that the best explanation of imaginative resistance invokes cognitive imagination but not conative imagination, then imaginative resistance functions as a data point that pushes us, if only weakly, toward the currently dominant position.

With this broader debate in mind, we will examine different accounts of imaginative resistance and draw out their cognitive architectural commitments in sections 3-5. Specifically, we will focus on where in the mind different accounts locate the experienced constraint that characterizes imaginative resistance. Before we can do so, we will give an overview of the puzzling psychological phenomenon in question.

\section{Imaginative Resistance}

\subsection{Phenomenon and Puzzles}

Arguably, contemporary philosophical discussions of imaginative resistance began with Walton (1994: 31; but see also Walton 1990; Moran 1994; Gendler 2000), who noted a curious asymmetry while echoing a passage from David Hume (1757):

If we find the perspective presented in a story [morally] offensive enough, we may object even to imagining taking it up. We might refuse to empathize with a character who accepts it, to put ourselves imaginatively in her shoes. We usually don't flinch at imagining accepting as true nonmoral propositions that we firmly believe to be false: the proposition that there is a ring that makes its wearer invisible, or that a village in Scotland appears and disappears every hundred years.

On a first pass, the asymmetry that Walton points to is that we do not resist imagining non-moral propositions that we do not believe in, but we do resist imagining moral propositions we do not believe in.

What is an example of a moral proposition that we resist imagining? Walton (1994) offers the following: 
Giselda. In killing her baby, Giselda did the right thing; after all, it was a girl.

Suppose the reader reads this sentence as part of a story's text (hereafter, when the reader encounters "Giselda"). The reader is likely to have several related reactions that give rise to distinctive philosophical puzzles (Liao and Gendler forthcoming; see also Weatherson 2004 and Walton 2006):

1. Imaginative Puzzle. Why does the reader have difficulty imagining that Giselda really did the morally right thing?

2. Fictionality Puzzle. Why does the reader have difficulty accepting that it is fictional, or true in the story world, that Giselda really did the right thing?

3. Phenomenological Puzzle. Why does the reader experience a sense of jarring confusion in response to the sentence?

4. Aesthetic Value Puzzle. Why does the reader think or judge that the story would be aesthetically superior if this sentence were omitted?

Given the complexity of imaginative resistance, it is no wonder that Walton (2006) wryly remarks 'the puzzle of imaginative resistance' is a composed of a series of misnomers, except the word 'of' it is not just one puzzle, but several puzzles, and not all of them have to do with imagination or with resistance. ${ }^{3}$ We will focus on the puzzles that have to do with psychological aspects of imaginative resistance, namely the imaginative and phenomenological puzzles. ${ }^{4}$ Both are concerned with how readers psychologically respond to sentences like the one above, which evoke imaginative resistance.

Imaginative resistance should be distinguished from the related phenomenon of hermeneutic recalibration, which is a common literary technique of temporarily puzzling the reader so as to cause her to reconsider and reinterpret the imaginative prompt (Liao 2013). In cases of hermeneutic recalibration, one eventually comes to a relatively stable understanding of the imaginative prompt. For example, one can feel like one can finally make sense of an initially puzzling sentence. However, in cases of imaginative resistance, even after multiple attempts to reconsider and reinterpret the imaginative prompt, the characteristic reactions-the difficulties with imagining and accepting the puzzling proposition, the experience of jarring confusion, and the thought that the work would be aesthetically better off without the puzzling proposition-persist.

Even if we restrict our discussion to cases involving persistent perplexity, there remain disagreements about the scope of the phenomenon. For example, while

\footnotetext{
${ }^{3}$ In fact, nothing hangs on the name "imaginative puzzle". We are merely using it as a placeholder for the puzzle in this vicinity that is concerned with the reader's psychological attitudes toward puzzling stories like Giselda. As we will see in section 5 , it could turn out that, on the best overall explanation of imaginative resistance, imagination plays no fundamental role in explaining the so-called imaginative puzzle.

${ }^{4} \mathrm{On}$ an alternative formulation, the imaginative puzzle too has a normative dimension and is perhaps better characterized as the imaginability puzzle (Liao 2011; Liao and Gendler forthcoming; Stear manuscript; Todd 2009). On this alternative formulation, the emphasis is on why the reader ought not imagine that Giselda really did the morally right thing while imaginatively engaging with the story, regardless of the reader's actual difficulty with imagining so. On this alternative formulation, there is a close relationship between the imaginative puzzle and the fictionality puzzle because what is fictional is equivalent to what is to be imagined (see Walton 1990; but see also the caveats added by Walton 2013).
} 
Tamar Szabó Gendler $(2000,2006)$ argues for the centrality of moral deviance to resistance phenomena, others think that imaginative resistance can also arise with cases of aesthetic deviance, epistemic deviance, etc. (for example, Walton 1994, 2006; Weatherson 2004; Yablo 2002). Hence, our first pass at the asymmetry that defines imaginative resistance will have to be refined accordingly to reflect these scope disagreements. Moreover, these disagreements about the exact explanandum constitute one source for the conflicting explanans of imaginative resistance. Indeed, as we will see next, these disagreements about scope can even make other philosophers doubt the existence of the whole phenomenon.

\subsection{Skepticism about Imaginative Resistance}

On our treatment, the phenomenon of imaginative resistance functions as a data point in resolving cognitive architectural debates about imagination. However, it is only fair to note that whether it really counts a data point is in contention. There exists a group of philosophers-call them imaginative resistance doubters-who have expressed skepticism about the very existence of a philosophical problem in the vicinity.

Imaginative resistance doubters contend that there is no such a thing as imaginative resistance per se. Rather, they maintain, the appearance of a philosophical problem arises from the bizarre so-called stories that philosophers have concocted. Nothing like the imaginative or phenomenological puzzles arises with narratives we ordinarily encounter in non-philosophical contexts. Consider the following statement, from Mary Mothersill (2003: 90):

[...] a fictional world is not created by a single proposition and hence that whether that proposition is or is not imaginable is otiose. [...] to grasp the moral content of a novel, you have to read the whole novel.

Imaginative resistance, the doubters contend, can at most be found in philosophers' poor attempts at literature. It is only because they have focused on single propositions divorced from context - or one-page stories constructed for the sake of making a philosophical point - that philosophers think there is a problem to be explained (Todd 2009). The doubters contend that propositions that are alleged to evoke imaginative resistance typically cease to do so once appropriate context is given (modulo some relativity regarding general imaginative capacity).

There is a core insight that can be gleaned from the doubters' arguments: imaginative resistance is not a phenomenon about particular propositions; instead it is a phenomenon about the interactions between particular propositions and particular contexts. While affirming the existence of the phenomenon, recent accounts of imaginative resistance have incorporated the core insight of the doubters to refine the puzzles and solutions associated with the phenomenon (see, for example, Brock 2012 and Liao, Strohminger, and Sripada 2014). 


\section{Cognitive Imagination Accounts}

Cognitive imagination accounts typically invoke cognitive imagination in conjunction with other relatively uncontroversial attitudes or processes (for example, belief and desire) in their explanations of imaginative resistance. Given that these explanations appeal to cognitive imagination and other attitudes or processes, these accounts can vary with respect to the degree to which cognitive imagination is central to explaining the phenomenon. However, despite such differences, they nevertheless share the core feature of placing the constraint that one experiences during imaginative resistance on cognitive imagination.

Although they are not always explicit, these accounts typically take conative imagination to be unnecessary for explaining imaginative resistance. Hence, insofar as these accounts are successful, they push us toward the position in the cognitive architectural debate that accepts cognitive imagination and rejects conative imagination.

We discuss four types of cognitive imagination accounts below. The distinction between these accounts does not necessarily imply strict incompatibility between them. For example, it might turn out that different accounts provide plausible descriptions of different aspects of the phenomenon of imaginative resistance. Or, it might turn out that an account is plausible at one level of description (for example, the personal level), while another is plausible at another level of description (for example, the subpersonal level).

\subsection{Single Code for Cognitive Imagination and Belief}

One type of cognitive imagination account appeals to the functional and representational similarities between cognitive imagination and belief to explain imaginative resistance.

According to a now widely-accepted hypothesis, cognitive imagination and believe operate on a single code: they share three key characteristics (Nichols 2004, 2006). First, cognitive imagination has belief-like propositional content. The same proposition, such as $<$ Mitt Romney is the President of the United States $>$, can be taken on by both cognitive imagination and belief. Second, cognitive imagination displays belief-like inferential regularities (Leslie 1987). When one believes the proposition <if a cup filled with water is upturned, it is now empty $>$ and the proposition <a cup filled with water is upturned $>$, then one is strongly disposed to believe the proposition <the cup is now empty>. Similarly, when one cognitively imagines the proposition <if a cup filled with water is upturned, it is now empty> and the proposition < a cup filled with water is upturned $>$, then one is strongly disposed to cognitively imagine the proposition <the cup is now empty $>$. Third, and most importantly, cognitive imagination has belief-like functional connections to moral and affect systems-as we will quickly see below.

Shaun Nichols $(2004,2006)$ argues, on the basis of this picture, that imaginative resistance is best explained by the hypothesis that cognitive imaginings are processed by a moral system in the same way that analogous beliefs are processed. 
When one believes that a mother kills her baby merely because the baby is a girl, one's moral system typically produces responses of condemnation. Similarly, when one cognitively imagines-when encountering "Giselda"-that a mother kills her baby merely because the baby is a girl, one's moral system typically produces responses of condemnation too. Given these responses of condemnation, one encounters difficulties with cognitively imagining-when encountering "Giselda"that the mother did the morally right thing.

Jonathan Weinberg and Aaron Meskin (2006; see also Meskin and Weinberg 2011) propose a similar idea. On their explanation, imaginative resistance arises from a conflict between different cognitive systems. When one encounters "Giselda", there exists a conflict between one's representation input system-cognitive imagination - that takes in the explicitly stipulated moral deviance (namely, Giselda did the morally right thing) as its content, and one's moral system that makes an independent judgment (namely, Giselda did not do the morally right thing) on the basis of the fictional scenario's relevant non-moral features. The account by Weinberg and Meskin is peculiar in that it allows for the cases where there is moral deviance but imaginative resistance does not arise (see also Weinberg 2008). On their explanation, these cases are possible because under certain circumstances either the relevant representation input system or the relevant processes within the moral system can be locally suspended so that no psychological conflict arises. (We will say more about these cases in section 3.3.)

\subsection{Cognitive Imagination + Belief about the World}

Another type of cognitive imagination accounts appeals to the interactions between cognitive imagination and belief to explain imaginative resistance. To start, we will focus on accounts that focus on interactions between cognitive imaginings and beliefs about the real world (as opposed to beliefs about the imaginative prompt itself).

In particular, many of these accounts focus on the supervenience relationships that hold in the real world. On their diagnoses, imaginative resistance is the manifestation of the inability to cognitively imagine stories that involve higherlower inconsistencies (Walton 1994, Weatherson 2004, Miyazono manuscript, Stear manuscript). These inconsistencies can arise with propositions that are true, when they are true, in virtue of the truth of other propositions. For example, some philosophers think that a proposition about an action's moral status is true, when it is true, in virtue of the truth of other propositions about non-moral features of that action, such as propositions about the harms that the action causes. In this example, the moral propositions are higher-level and the non-moral propositions are lowerlevel. What is peculiar about prompts that evoke imaginative resistance, such as "Giselda", is that they involve inconsistencies between the higher- and lower-level propositions that one is supposed to cognitively imagine.

Higher-lower inconsistencies arise because we have beliefs about how higher-level propositions should relate to lower-level propositions, which we import into our imaginative engagements. For example, we might think that, insofar as 
female infanticide can be the morally right thing to do in some cases, it is only because of some explicable reason like not committing the female infanticide would cause more deaths. When one encounters "Giselda" without additional context, no such explicable reason is present, and so given our belief in the relationship between moral and non-moral propositions, we cannot cognitively imagine the higher-level moral proposition (namely, Giselda did the morally right thing) given what we have cognitively imagined at the lower level (namely, Giselda killed the baby just because the baby is a girl). As Brian Weatherson (2004: 21) notes, "we can imagine the higher-level claim only some way or another, just as we imagine a chair only as some chair or other". We cannot cognitively imagine the moral proposition, because the non-moral propositions we cognitively imagined do not constitute one of the ways of realizing the moral rightness of female infanticide.

Of course, the relevant beliefs about the world that affect our cognitive imaginings need not be beliefs about supervenience relationships. For example, Cain Todd (2009) speculates that deontologists and utilitarians might respond differently to the same stories that are alleged to evoke imaginative resistance. More generally, one's background belief about (meta)ethical issues might shape one's cognitive imaginings differently. Difference in background beliefs about (meta)ethical issues might help to explain some individual differences in imaginative resistance that some philosophers have observed.

\subsection{Cognitive Imagination + Belief about the Imaginative Prompt}

Continuing our focus on accounts that use interactions between cognitive imagination and belief to explain imaginative resistance, we now turn to accounts that focus on interactions between cognitive imaginings and beliefs about the imaginative prompt (as opposed to beliefs about the real world). On these accounts, during imaginative engagements with particular prompts, our cognitive imaginings are shaped by beliefs that we have about the prompts.

The most notable variant of this type of accounts appeals to beliefs about genre conventions that govern stories (Gendler 2000, Weinberg 2008, Nanay 2010, Liao 2011, Willard manuscript). On their diagnoses, the relevant constraints on cognitive imagination do not come from beliefs about the real world, but beliefs about fictional worlds. For example, while few people believe that divine command theory is true of the real world, many more believe that divine command theory is true of fictional worlds of creation myths and other religious stories. As such, while few people believe that the truth of moral propositions supervene on the truth of non-moral propositions about God or gods' pronouncements, many more believe that the fictional truth of moral propositions supervene on the fictional truth of nonmoral propositions about God or gods' pronouncements, when it comes to creation myths and other religious stories. The belief about divine command theory being true in creation myths and other religious stories is an example of a belief about genre conventions. These accounts can explain why the same proposition can be puzzling in one story but not another, when two stories belong to different genres and so are governed by different conventions. 
It is possible to incorporate the role of beliefs about the imaginative prompt into accounts of imaginative resistance discussed earlier. For example, Weinberg (2008) modifies the earlier account in Weinberg and Meskin (2006) to make explicit the role of beliefs about genre conventions. Recall that on Weinberg and Meskin's original account, imaginative resistance arises from a conflict between cognitive systems, but conflicts can be avoided when one cognitive system can be "locally suspended". According to Weinberg (2008), beliefs about genre conventions constitute one way to locally suspend the moral system-or, more precisely, to locally suspend the typical connection between cognitive imagination and the moral system - such that no conflict arises.

This type of imaginative resistance accounts has recently received some support regarding its empirical adequacy. Shen-yi Liao, Nina Strohminger, and Chandra Sekhar Sripada (2014) reports two empirical studies they conducted to show that beliefs of genre conventions can influence one's imaginative responses to fictions. Study 1 shows that there is a correlation between one's familiarity with a genre, which affects the likelihood that one correctly believes the relevant genre conventions, and one's experienced difficulty in cognitively imagining a morally deviant proposition. Study 2 finds that manipulating governing genre conventions makes the same morally deviant proposition relatively difficult to cognitively imagine in one story but not in another.

\subsection{Cognitive Imagination + Desire}

The final type of cognitive imagination accounts appeals to the interactions between cognitive imagination and desire to explain imaginative resistance. According to these accounts, the difficulty with cognitively imagining puzzling propositions is not a kind of inability, but a kind of unwillingness.

Gendler $(2000,2006)$ provides the paradigmatic example of this type of accounts. Gendler (2000) notes that resistance-evoking stories are what she calls "non-distoring fictions". Something that is true in the real world is likely to be true in these fictional worlds, and more importantly, something that is true in these fictional worlds is likely to be in true in the real world. Hence, if we judge something as true in these stories, there is a prima facie demand that we judge it as true in the real world as well. For example, if we are to cognitively imagine that Giselda's female infanticide is morally right, then there is pressure on us to believe that analogous cases of female infanticide in the real world are morally right as well. However, as Gendler notes, we have strong desire not to believe that analogous cases of female infanticide are morally right in reality, and so this in turn pressures us not to cognitively imagine that Giselda's female infanticide is morally right. As Gendler (2000: 77) puts the point: "my hypothesis is that cases that evoke genuine imaginative resistance will be cases where the reader feels that she is being asked to export a way of looking at the actual world which she does not wish to add to her conceptual repertoire."

Gendler (2006) provides a refinement of the earlier account on which desire plays a less central role in explaining imaginative resistance. Moran (1994) and 
Currie (2011) can also be seen as proponents of accounts that give desire a significant role in explaining imaginative resistance, sometimes via emotions that are generated by the relevant desires.

\section{Conative Imagination Accounts}

Conative imagination accounts invoke both cognitive and conative imagination in their explanations of imaginative resistance. As the name indicates, a core feature that these accounts share is that they place the constraint that one experiences during imaginative resistance on conative imagination. Insofar as these accounts are successful, they push us toward the position in the cognitive architectural debate that accepts both cognitive and conative imagination.

\subsection{Desire-like Imagination}

There seems to be an asymmetry between supposing and imagining a morally deviant proposition. We seem to have no trouble supposing that female infanticide is morally right without any further explanation for the purpose of, say, philosophical arguments. However, as our responses to "Giselda" shows, we do have trouble imagining that female infanticide is morally right, absent some explanation.

Gregory Currie (2004) gives an interpretation of this asymmetry at the cognitive architectural level. What we ordinarily call "imagination" is the use of both cognitive and conative imagination. In contrast, what we ordinarily call "supposition" is the use of cognitive imagination without the accompaniment of conative imagination. On this interpretation, the fact that we can easily suppose the moral rightness of female infanticide but cannot easily imagine so is evidence that cognitive imagination does not play a central role in explaining imaginative resistance. In fact, the explanatory work is done by a specific version of conative imagination that he calls "desire-like imagination".

Whereas to desire something is to want it to be the case in the real world, to desire-like imagine something is to want it to be the case in some imagined or fictional world. However, Currie says that there is an important difference between the dissociability between cognitive imagining and belief and the dissociability between desire-like imagining and desire. While we can easily cognitively imagine something we do not believe, we cannot easily desire-like imagine something we do not desire. Hence, for the majority of people who do not in fact desire that female infanticide for no obvious reason is morally right, it is difficult to desire-like imagine that female infanticide for no obvious reason is morally right. And this difficulty to desire-like imagine so is what explains the difficulty with imagination that "Giselda" brings out. 


\subsection{Value-like Imagination}

Dustin Stokes (2006) revises Currie's account and argues that the relevant conative imaginative attitude is not Currie's desire-like imagination but what he calls "valuelike imagination". Stokes relies on David Lewis's (1989) picture of valuing, on which to value something is to have a second-order desire of that thing: to value $x$ is to desire that one desires $x$. On Stokes's account, imaginative resistance is best explained by value-like imagination, an attitude to want oneself to want something to be the case in some imagined or fictional world.

Stokes argues that desire-like imagination is insufficient to explain imaginative resistance. For example, it is not clear how Currie's view explains why we experience imaginative resistance with a story that says that a really dumb Knock-Knock joke is hilariously funny (Walton 1994). We have no actual desire about the joke and its funniness. So there is no reason to think that our desire-like imagination is constrained by any actual desire in this case. However, there is reason to think that it would be a part of our value system that the dumb joke is not hilariously funny: we do not want it to be true of ourselves that we want the dumb joke to be funny. Hence, given the relatively low dissociability between value-like imagining and value, we cannot easily value-imagine that a really dumb KnockKnock joke is hilariously funny.

\section{No Imagination Accounts}

No imagination accounts bypass imaginative attitudes altogether in their explanations of imaginative resistance. In other words, on these accounts neither cognitive nor conative imagination - as they are standardly characterized-factor in understanding the psychology of imaginative resistance at the fundamental level. They place the constraint that one experiences during imaginative resistance on neither cognitive nor conative imagination, but elsewhere in cognitive architecture. Hence, insofar as these accounts are successful, they push us toward the position in the cognitive architectural debate that rejects both cognitive and conative imagination.

\subsection{Alief}

In an evolution of her earlier views, Gendler (2008a, 2008b) argues that imaginative contagion, cases where (merely) imaginative engagement with fictions can reshape our real-world moral views, may ultimately be traced to a novel psychological state that she calls "alief". Roughly, aliefs are innate or habitual propensities to respond to apparent stimuli in automatic and associative ways. According to Gendler (2008b), aliefs are antecedent to other cognitive attitudes, including belief and cognitive imagination: "Indeed, one might even argue that it is out of these more primitive association patterns [that constitute aliefs] ... that the less fundamental differentiated attitudes like belief, desire, and imagination are constructed" (643; our emphases). Alief is unlike imagination in some ways; for example, aliefs tend to be opaque to the 
subject: they are not generally available for introspective access. However, alief is also like imagination in other ways; for example, they are both to a degree sourceinsensitive: they need not track how the subject consciously conceives of the world.

Although Gendler never explicitly spells out, in print, the implication of alief for explaining imaginative resistance, the relative source-insensitivity of aliefs suggests a relatively straightforward proposal. Since aliefs are source-insensitive, even contents we consciously recognize as purely imaginary can produce powerful emotional and cognitive responses of the sort that underpin imaginative contagion. Not all contents do so, of course. However, plausibly our deeply held moral commitments are just the sort of content that would be encoded in aliefs, such that being asked to imagine that Giselda's female infanticide is morally right would trigger psychological responses that are characteristic of imaginative resistance. Given the importance Gendler now places on aliefs, it is plausible that she thinks that, at least for some questions concerning imaginative resistance, a psychological framework at the level of aliefs can provide better explanations than a psychological framework at the level of cognitive imaginings.

If Gendler is right that alief is more primitive and fundamental than cognitive imagination, then the most fundamental cognitive architecture no longer contains cognitive imagination or belief as sui generis attitudes. In turn, a psychological explanation of imaginative resistance at this fundamental cognitive architectural level does not locate the constraint that one experiences during imaginative resistance in cognitive imagination (or conative imagination, for that matter); instead, it locates that constraint in alief. Hence, we count this a no imagination account because it plausibly bypasses all imaginative attitudes in explaining imaginative resistance.

Considering how Gendler's most recent account differs from her earlier ones is also useful for bringing out the theoretical value of our cognitive architectural re-orientation of the imaginative resistance literature. Although Gendler's understanding of the phenomenon of imaginative resistance itself has only subtly evolved throughout the years, the alief-based account is a substantial departure from the imagination-based account at the cognitive architectural level. It would be harder to detect this substantial change in her overall position using existing taxonomies of positions in the imaginative resistance debate.

\subsection{Emotion}

Ronald De Sousa (2010) argues that emotion plays a central role in generating imaginative resistance. On this view, imagination is unconstrained, but emotional responses to imaginings are constrained. Imaginative resistance is the product of constraints on emotional responses: "what is really going on in these cases is not so much an inability to imagine, but to experience a certain emotional response (or an absence of emotional response) to something imagined" (De Sousa 2010: 108).

On this account, a story evokes imaginative resistance when (1) one part of the story generates some emotional response that does not fit with what another part of the story asks us to imagine, or (2) when one part of the story fails to generate 
some emotional response that fits with what another part of the story asks us to imagine. For an example of (1), we can revisit what happens when one encounters "Giselda". We respond to the claim that Giselda killed her baby just because the baby was a girl with disapprobation and disgust, which does not fit with also imagining that what she did is morally right. For an example of (2), we can revisit the KnockKnock joke story. We fail to respond to the dumb Knock-Knock joke with mirth, which is the emotion that fits with imagining that the joke is hilariously funny.

Note that De Sousa's account is distinct from other accounts that invoke emotion in connection with cognitive imagination and other attitudes (Moran 1994; Currie 2011; Van Leeuwen forthcoming). On these other accounts, it is still imagination, perhaps in interaction with other attitudes such as desire, that ultimately explains imaginative resistance; emotions are just mediators in the explanation. However, on De Sousa's account, the experienced constraint that characterizes imaginative resistance directly comes from constraints on emotions. Hence, we count this as a no imagination account too.

\section{Directions for Future Research}

In this chapter, we have given an introduction to the phenomenon of imaginative resistance from the perspective of cognitive architecture, with special attention to imaginative attitudes' role in explaining this phenomenon. By dividing up accounts of imaginative resistance based on their psychological commitments, we have also laid the groundwork for theorizing about the mind using the phenomenon of imaginative resistance.

Of course, the task of theorizing the mind using the phenomenon of imaginative resistance may be complicated by the very nature of imaginative resistance. Although we have treated imaginative resistance as a unified phenomenon, ongoing disagreements about its scope suggests that there may be multiple related phenomena in the vicinity that demand different psychological explanations (Currie and Ichino 2013). If that were the case, then we must approach the task piecemeal and consider the different cognitive architectural implications of different psychological explanations.

The new orientation we have developed in this handbook chapter can spur further progress on the elusive phenomenon of imaginative resistance and the equally elusive attitude(s) of imagination in other ways:

Aestheticians who work on imaginative resistance can be more explicit about their cognitive architectural commitments and also about cognitive architectural commitments of competing explanations.

- Philosophers of mind who work on imagination can make holistic assessments of competing cognitive architectures by examining a wide range of psychological phenomena that are primarily discussed in cognate subfields.

- Psychologists and experimental philosophers can design better studies of imaginative resistance by considering its potential psychological commitments, which can lead to new discoveries about aspects of imaginative resistance that are less readily accessible to introspection or intuition. 


\section{References}

Brock, S. (2012) “The Puzzle of Imaginative Failure,” The Philosophical Quarterly 62: 443-463.

Currie, G. (2002) "Desire in Imagination," in T. S. Gendler and J. Hawthorne (eds.), Conceivability and Possibility, New York: Oxford University Press, 201-21.

Currie, G. and Ravenscroft, I. (2002) Recreative Minds: Imagination in Philosophy and Psychology, New York: Oxford University Press.

Currie, G. (2011).Narratives and Narrators: A Philosophy of Stories. New York: Oxford University Press.

Currie, G. and Ichino, A. (2013) "Imagination and Make-Believe," in B. Gaut (eds.), The Routledge Companion to Aesthetics, $3^{\text {rd }}$ edition, 320-329.

De Sousa, R. (2010) “The Mind's Bermuda Triangle: Philosophy of Emotions and Empirical Science," in P. Goldie (ed.), The Oxford Handbook of Philosophy of Emotion, New York: Oxford University Press, 95-117.

Doggett, T. and Egan, A. (2007) “Wanting Things You Don't Want," Philosophers' Imprint 7(9): 1-17.

Doggett, T. and Egan, A. (2012) "How We Feel About Terrible, Non-existent Mafiosi," Philosophy and Phenomenological Research 84(2): 277-306.

Funkhouser, E. and Spaulding, S. (2009) "Imagination and Other Scripts," Philosophical Studies 143(3): 291-314.

Gendler, T. S. (2000) "The Puzzle of Imaginative Resistance," The Journal of Philosophy 97(2): 55-81.

Gendler, T. S. (2006) "Imaginative Resistance Revisited," in S. Nichols (ed.), The Architecture of the Imagination: New Essays on Pretence, Possibility, and Fiction, New York: Oxford University Press, 149-173.

Gendler, T. S. (2008a) “Alief and Belief," The Journal of Philosophy 105(10): 634-663.

Gendler, T. S. (2008b) "Alief in Action (and Reaction)," Mind and Language 23(5): 552-585.

Gendler, T. S. (2011) "Imagination," in E. N. Zalta (ed.), Stanford Encyclopedia of Philosophy. Stanford: Center for the Study of Language and Information, Stanford University, Spring 2011 edition, URL = $<$ http://plato.stanford.edu/archives/fall2011/entries/imagination/>.

Hume, D. (1757) "Of the Standard of Taste," in Essays: Moral, Political and Literary, Vol. 1, London: Longmans, Green, and Co, 231-258

Kind, A. (2011) “The Puzzle of Imaginative Desire," Australasian Journal of Philosophy 89(3): 421-39.

Kind, A. (2013) “The Heterogeneity of the Imagination," Erkenntnis 78(1): 141-159.

Langland-Hassan, P. (2012) "Pretense, Imagination, and Belief: the Single Attitude Theory," Philosophical Studies 159(2): 155-79.

Langland-Hassan, P. (2014) "What It Is To Pretend," Pacific Philosophical Quarterly 95(1): 397-420.

Leslie, A. (1987) "Pretense and Representation," Psychological Review 94(4): 412-26.

Leslie, A. (1994) "Pretending and Believing," Cognition 50: 211-38. 
Lewis, D. (1989) "Dispositional Theories of Value," Proceedings of the Aristotelian Society 63: 113-137.

Liao, S. (2011) On Morals, Fictions, and Genres. PhD Thesis, University of Michigan.

Liao, S. (2013) "Moral Persuasion and the Diversity of Fictions," Pacific Philosophical Quarterly 94(3): 269-289.

Liao, S. and Doggett, T. (2014) "The Imagination Box," The Journal of Philosophy 111(5): 259-275.

Liao, S. and Gendler, T. S. (forthcoming). "The Problem of Imaginative Resistance," in J. Gibson and N. Carroll (eds.), The Routledge Companion to Philosophy of Literature, New York: Routledge.

Liao, S., Strohminger, N., and Sripada, C. S. (2014) "Empirically Investigating Imaginative Resistance," British Journal of Aesthetics 54(3): 339-355.

Meskin, A. and Weinberg, J. (2011) "Imagination Unblocked," in E. Schellekens and P. Goldie (eds.) The Aesthetic Mind: Philosophy and Psychology, New York: Oxford University Press, 239-253.

Miyazono, K. (manuscript) “Unstable Imaginative Resistance,” University of Birmingham.

Moran, R. (1994) “The Expression of Feeling in Imagination,” The Philosophical Review 103(1): 75-106.

Mothersill, M. (2003) "Make-Believe Morality and Fictional Worlds," in J. L. Bermúdez and S. Gardner (eds.), Arts and Morality, New York: Routledge, 7494.

Nanay, B. (2010) "Imaginative Resistance and Conversational Implicatures," The Philosophical Quarterly 60: 586-600.

Nichols, S. (2004) "Imagining and Believing: The Promise of a Single Code," The Journal of Aesthetics and Art Criticism 62(2): 129-139.

Nichols, S. (2006) “Just the Imagination: Why Imagining Doesn't Behave Like Believing," Mind and Language 21(4): 459-474.

Nichols, S. and Stich, S. (2003) Mindreading: An Integrated Account of Pretense, SelfAwareness, and Understanding Other Minds, New York: Oxford University Press.

Schellenberg, S. (2013) "Belief and Desire in Imagination and Immersion," The Journal of Philosophy 110(9): 497-517.

Stear, N. (manuscript) "On the Imaginative and Fictionality Puzzles," University of Michigan.

Stokes, D. (2006) “The Evaluative Character of Imaginative Resistance," British Journal of Aesthetics 46(4): 387-405.

Tanner, M. (1994) "Morals in Fiction and Fictional Morality (II)," Supplement to the Proceedings of the Aristotelian Society 68: 51-66.

Todd, C. (2009) "Imaginability, Morality, and Fictional Truth: Dissolving the Puzzle of 'Imaginative Resistance'," Philosophical Studies 143(2): 187-211.

Van Leeuwen, N. (2011) "Imagination is Where the Action Is," The Journal of Philosophy 108(2): 55-77.

Van Leeuwen, N. (2013) “The Meanings of 'Imagine' Part 1: Constructive Imagination," Philosophy Compass 8(3): 220-230. 
Van Leeuwen, N, (forthcoming) "The Imaginative Agent," in A. Kind and P. Kung (eds.), Knowledge through Imagination, New York: Oxford University Press.

Walton, K. L. (1990) Mimesis as Make-Believe: On the Foundations of the Representational Arts, Cambridge: Harvard University Press.

Walton, K. L. (1994) "Morals in Fiction and Fictional Morality (I)," Supplement to the Proceedings of the Aristotelian Society 68: 27-50.

Walton, K. L. (2006) "On the (So-called) Puzzle of Imaginative Resistance," in S. Nichols (ed.), The Architecture of the Imagination: New Essays on Pretence, Possibility, and Fiction, New York: Oxford University Press, 137-148.

Walton, K. L. (2013) "Fictionality and Imagination Reconsidered," in C. Barbero, M. Ferraris, and A. Voltolini (eds.), From Fictionalism to Realism, Newcastle upon Tyne: Cambridge Scholars Publishing, 9-26.

Weatherson, B. (2004) “Morality, Fiction, and Possibility," Philosophers' Imprint 4(3): $1-27$.

Weinberg, J. M. (2008) “Configuring the Cognitive Imagination," in K. Stock and K. Thomsen-Jones (eds.), New Waves in Aesthetics, New York: Palgrave Macmillan, 203-223.

Weinberg, J. and Meskin, A. (2006a) "Imagine That!," in M. Kieran (ed.), Contemporary Debates in Aesthetics and the Philosophy of Art, Cambridge: Blackwell, 222-235.

Weinberg, J. and Meskin, A. (2006b) "Puzzling Over the Imagination" in S. Nichols (ed.), The Architecture of the Imagination: New Essays on Pretence, Possibility, and Fiction, New York: Oxford University Press, 175-202.

Willard, M.B. (manuscript) "Stop over-Analyzing It: The Puzzle of Historical Inaccuracy and the Pragmatic Interpretation of Imaginative Resistance," Weber State University.

Yablo, S. (2002) "Coulda, Woulda, Shoulda," in T. S. Gendler and J. Hawthorne (eds.), Conceivability and Possibility, New York: Oxford University Press, 441492. 